\title{
Bioaccumulation and photosynthetic activity response of sweet sorghum seedling (Sorghum bicolor L. Moench) to cadmium stress
}

\author{
Z.C. XUE*, J.H. LI*, D.S. LI*, S.Z. LI", ${ }^{*}$, C.D. JIANG ${ }^{* *}$, L.A. LIU**, S.Y. WANG ${ }^{* *}$, and W.J. KANG ${ }^{* *}$ \\ Institute New Energy Technology, Tsinghua University, Beijing 100084, China* \\ Institute of Botany, The Chinese Academy of Sciences, Beijing, 100093, China ${ }^{* *}$
}

\begin{abstract}
A hydroponic experiment was conducted to investigate bioaccumulation and photosynthetic activity response to $\mathrm{Cd}$ in sweet sorghum seedlings. The seedlings were treated with 0,50 , and $100 \mu \mathrm{M} \mathrm{Cd}$ for $15 \mathrm{~d}$. Our results showed that morphological characteristics of sweet sorghum were significantly affected by $\mathrm{Cd}$ treatments. The $\mathrm{Cd}$ concentrations in roots and shoots increased with increasing $\mathrm{Cd}$ concentrations in the nutrition solution; higher $\mathrm{Cd}$ accumulation was observed in the roots. Meanwhile, the photosynthetic activity decreased significantly and a shape of chlorophyll (Chl) $a$ fluorescence transient in leaves was altered by $\mathrm{Cd}$ treatments. The $\mathrm{Chl}$ contents in the leaves decreased significantly, which was demonstrated by a change of spectral reflectance. Our data indicated that the higher $\mathrm{Cd}$ concentration reduced $\mathrm{Chl}$ contents and inhibited electron transport in the leaves, leading to the decrease of photosynthetic activity.
\end{abstract}

Additional key words: chlorophyll a fluorescence; energy plant; photosynthetic activity; soil contamination; spectral reflectance.

\section{Introduction}

Soil contamination with heavy metals has become a critical environmental issue throughout the world. Cadmium, which is one of the main toxic heavy metals in agricultural soils, is not needed by plants. It is mainly coming from livestock manures, atmospheric deposition, and fertilizers (Luo et al. 2009). Because of its high rate of soil-to-plant transfer, $\mathrm{Cd}$ can be easily acquired by plants, leading to inhibition of the growth and productivity of crops. Cd is efficiently retained by kidney and liver in the human body and it results in health issues after entering food chain (Satarug et al. 2010, Yuan et al. 2014, Zhong et al. 2015). Therefore, it is an urgent and necessary need to remediate the $\mathrm{Cd}$ contaminated agricultural soils for minimizing environmental impacts and ensure the safety of food. Although various chemical (leaching and fixation) and physical (soil replacement, thermal desorption) methods have been used successfully for soil remediation, these methods are relatively expensive and are often unable to remove contamination completely. So phytoremediation has been adopted due to its costeffective, nonintrusive, and ecofriendly nature (Gomes et al. 2016). Then, some researchers have suggested that using energy plants (Gomes 2012), such as maize (Vigliotta et al. 2016), rape seed (van Ginneken et al. 2007), and sweet sorghum (Tian et al. 2015, Zhuang et al. 2009) as phytoremediation plants, because of their rapid growth and high biomass production.

Received 17 August 2017, accepted 7 February 2018, published as online-first 21 June 2018.

${ }^{+}$Corresponding author; phone: (86)010-62772123, e-mail: szli@mail.tsinghua.edu.cn

Abbreviations: $\mathrm{ABS} / \mathrm{RC}$ - absorption flux per $\mathrm{RC} ; \mathrm{DI} / \mathrm{RC}$ - dissipated energy flux per RC at $\mathrm{t}=0$; DM - dry mass; $E-$ transpiration rate; $\mathrm{ET}_{\mathrm{o}} / \mathrm{RC}$ - electron transport flux per $\mathrm{RC}$ at $\mathrm{t}=0 ; \mathrm{F}_{\mathrm{I}}$ - fluorescence intensity at the I step (at $\left.30 \mathrm{~ms}\right) ; \mathrm{F}_{\mathrm{J}}$ - fluorescence intensity at the J step (at $2 \mathrm{~ms}$ ); $\mathrm{F}_{\mathrm{m}}$ - maximal fluorescence intensity; $\mathrm{F}_{\mathrm{o}}$ - fluorescence intensity at $20 \mu \mathrm{s} ; \mathrm{F}_{\mathrm{t}}$ - fluorescence emission from a darkadapted leaf at the time $t ; g_{s}-$ stomatal conductance; $\mathrm{mND}_{705}$ - modified red-edge normalized difference vegetation index; $\mathrm{M}_{\mathrm{o}}-\mathrm{slope}$ of the curve at the origin of the relative variable fluorescence rise; $\mathrm{mSR}_{705}$ - modified red-edge ratio; $\mathrm{PI}_{\mathrm{abs}}$ - performance index; $P_{\mathrm{N}}$ - net photosynthetic rate; $\mathrm{PRI}$ - photochemical reflectance index; RC - reaction center; $\mathrm{RC} / \mathrm{CS}_{\mathrm{o}}-\mathrm{Q}_{\mathrm{A}}$-reducing reaction centers per cross-section; $\mathrm{TF}$ - translocation factor; $\mathrm{TR}_{\mathrm{o}} / \mathrm{RC}$ - trapped energy flux per $\mathrm{RC}$ at $\mathrm{t}=0 ; \mathrm{V}_{\mathrm{t}}$ - relative variable fluorescence at the time $\mathrm{t}$; $\delta_{\mathrm{Ro}}$ - probability that an electron is transported from the reduced intersystem electron acceptors to the final electron acceptors of PSI; $\varphi \mathrm{Po}_{0}-$ maximum quantum yield for primary photochemistry; $\Psi_{\mathrm{Eo}}-$ probability that an electron moves further than $\mathrm{Q}_{\mathrm{A}}^{-}$.

Acknowledgments: This work was supported by the Ministry of Science and Technology of the People's Republic of China under Grant number 2013GS460202-3 of the Science and Technology Program for Public Wellbeing. 
Sweet sorghum [Sorghum bicolor (L.) Moench], which is considered as a great promising energy plant, shows a rapid growth, high yield, rich carbohydrate content in stalk, and wider adaptability (Almodares and Hadi 2009, Guo et al. 2018). The stalk yield of sweet sorghum can reach $60-90 \mathrm{t} \mathrm{ha}^{-1}$ and sugar content of $10-15 \%(\mathrm{w} / \mathrm{w})$. It is a good candidate for bioenergy production as s potential yield of sweet sorghum in producing ethanol is 3,0005,220 L ha ${ }^{-1}$ (Sathya et al. 2016). Previous studies have proved that sweet sorghum has the ability to absorb heavy metals (An 2004, Marchiol et al. 2007, Tian et al. 2015). Therefore, the phytoremediation technology based on sweet sorghum could effectively utilize the remedying plants to produce ethanol and power and prevent $\mathrm{Cd}$ contaminated agro-products from entering the food chain. Sweet sorghum can extract more than $0.05 \mathrm{~kg} \mathrm{ha}^{-1}$ of $\mathrm{Cd}$ in a single crop, when the diethylene triamine pentaacetic acid-extractable Cd concentrations is $1.02 \mathrm{mg} \mathrm{kg}^{-1}$ (soil) (Zhuang et al. 2009). Tian et al. (2015) study showed that the morphological characteristics of sweet sorghum were not significantly changed with the Cd concentration $\leq 5 \mathrm{mg}$ $\mathrm{kg}^{-1}$ (soil). However, a plant height and dry mass of S. bicolor decreased $27.6-28.5 \%$ and $38.7-51.5 \%$, respectively, when the $\mathrm{Cd}$ concentration in soil was $15 \mathrm{mg} \mathrm{kg}^{-1}$ (Wang et al. 2017). When the Cd concentration increased

\section{Materials and methods}

Plant materials and treatments: Sweet sorghum [Sorghum bicolor (L.) Moench, cv. BL0602] plants were grown in pots $(20 \mathrm{~cm}$ in diameter and $35 \mathrm{~cm}$ in height) containing quartz sand in a greenhouse. During the growth period, the average day/night temperatures were $32 / 20^{\circ} \mathrm{C}$, the relative humidity were $70-95 \%$, and midday PPFD was $800 \mu \mathrm{mol} \mathrm{m} \mathrm{m}^{-2} \mathrm{~s}^{-1}$. The plants were supplied daily with half-strength Hoagland solution to avoid any potential nutrient and drought stresses. The plants were thinned to three plants per pot $5 \mathrm{~d}$ after sowing. Then, Cd treatments were applied to the plants after two weeks. The treatment solutions were prepared with $\mathrm{CdNO}_{3} \cdot 2.5 \mathrm{H}_{2} \mathrm{O}$ to give $\mathrm{Cd}$ concentration of 0,50 , and $100 \mu \mathrm{M}$. The treatments continued for $15 \mathrm{~d}$. The sand was flushed with the sufficient treatment solution (about double amount of the water that the sand in the pot can hold) daily to maintain the concentration of nutrition minerals and $\mathrm{Cd}$ concentrations constant during the treatment period. The new fully expanded leaves were used for measurement of gas exchange, Chl $a$ fluorescence, and spectral reflectance.

Morphological response: The leaf area of the new fully expanded leaves was measured using a $L I-3000 C$ portable area meter (LI-COR Biosciences, USA). The number of leaves, root and shoot length was measured at the end of the experiment. Then the dry masses of the roots and shoots were determined under $80^{\circ} \mathrm{C}$ to constant mass. Fifteen replicate measurements were made for each treatment and the results were averaged. to $30 \mathrm{mg} \mathrm{kg}^{-1}$, shoot, leaf, and seed biomass of Yajin No.1 decreased to $68.7,75.1$, and $70 \%$, respectively (Tian et al. 2015). The inhibition of sweet sorghum growth under high $\mathrm{Cd}$ concentration occurs due to reduced photosynthetic activity in the leaves. Many studies have demonstrated that the decrease in photosynthetic rate under Cd stress might be a result of reduced Chl contents (Küpper et al. 1996, He et al. 2008), obstructed electron transport (Pagliano et al. 2006, Sigfridsson et al. 2004), as well as a perturbation of enzymes of $\mathrm{CO}_{2}$ fixation (Parmar et al. 2013). Although the effects of $\mathrm{Cd}$ on the photosynthetic activity have been assessed in a variety of plants, such as rice (Wang et al. 2014, He et al. 2008), maize (Silva et al. 2017, Lysenko et al. 2015, Wang et al. 2009), and soybean (Xue et al. 2013), the effects of $\mathrm{Cd}$ on photosynthetic activity of sweet sorghum leaves have received only limited attention.

Therefore, in order to assess the photosynthetic activity response of sweet sorghum to the Cd stress, we used hydroponics experimental with a higher concentration of Cd treatment [50 and $100 \mu \mathrm{m}$, approximately 5.62 and $11.24 \mathrm{mg} \mathrm{kg}^{-1}$ (soil)] to investigate gas exchange, Chl $a$ fluorescence, and spectral reflectance in the leaves of sweet sorghum. Then, the effects can be observed in a short time.

Gas exchange: The net photosynthetic rate $\left(P_{\mathrm{N}}\right)$, stomatal conductance $\left(g_{\mathrm{s}}\right)$, and transpiration rate $(E)$ were measured using a CIRAS-2 portable photosynthetic system (PP Systems, USA) on a sunny day between 9:30 and 11:00 h. (Xue et al. 2014). The atmospheric conditions in the leaf chamber were controlled by the CIRAS-2 during the measurement, the PPFD at $1,200 \mu \mathrm{mol} \mathrm{m} \mathrm{m}^{-2} \mathrm{~s}^{-1}$, temperature at $25^{\circ} \mathrm{C}$, and $\mathrm{CO}_{2}$ concentration at $360 \mathrm{mmol} \mathrm{mol}^{-1}$. The light was provided by a red/blue LED source. Five replicate measurements were made for each treatment, and the results were averaged.

Chl $\boldsymbol{a}$ fluorescence transient was measured using a Handy-PEA fluorometer (Hansatech, UK). Following dark adaptation for $20 \mathrm{~min}$, all leaves were immediately exposed to a saturating light pulse of 3,500 $\mu \mathrm{mol}$ (photon) $\mathrm{m}^{-2} \mathrm{~s}^{-1}$ by red light (peak at $650 \mathrm{~nm}$ ) for $2 \mathrm{~s}$. Each transient obtained from the dark-adapted samples was analyzed according to the JIP-test (Appendix) (Strasser et al. 2004, Salvatori et al. 2015, Chen et al. 2016). Fifteen replicate measurements were made for each treatment, and the results were averaged.

Spectral reflectance measurements were measured using a Unispec SC field portable spectrometer (PP Systems, USA). Leaf reflectance was measured with a bifurcated fiber optic cable and a leaf clip (models UNI410, PP Systems, Haverhill, MA). Leaf illumination was provided by a tungsten halogen lamp in the spectrometer. Thirty 
measurements were made for each treatment, and the results were averaged. A linear interpolation routine was used to estimate values at $1-\mathrm{nm}$ intervals prior to calculation of indexes. The following established vegetation indexes, which derived from spectral reflectance, were then calculated: ( 1$)$ the photochemical reflectance index $(\mathrm{PRI}), \mathrm{PRI}=\left(\mathrm{R}_{531}-\mathrm{R}_{570}\right) /\left(\mathrm{R}_{531}+\mathrm{R}_{570}\right)$ (Gamon et al. $1992)$; (2) the modified red-edge ratio $\left(\mathrm{mSR}_{705}\right), \mathrm{mSR}_{705}=$ $\left(\mathrm{R}_{750}-\mathrm{R}_{445}\right) /\left(\mathrm{R}_{705}-\mathrm{R}_{445}\right)$ (Sims and Gamon 2002); (3) the modified red-edge normalized difference vegetation index $\left(\mathrm{mND}_{705}\right), \mathrm{mND}_{705}=\left(\mathrm{R}_{750}-\mathrm{R}_{705}\right) /\left(\mathrm{R}_{750}+\mathrm{R}_{705}-2 \mathrm{R}_{445}\right)$ (Sims and Gamon 2002).

Cd concentrations: The dried roots and shoots of the sweet sorghum plants were grounded to fine powder and digested in $6 \mathrm{~mL}$ of a mixture of nitric acid and hydrogen

\section{Results and discussion}

The Cd concentrations in both roots and shoots of sweet sorghum seedling increased with increasing $\mathrm{Cd}$ concentrations in the Hoagland solution (Fig. 1A). It is well known that $\mathrm{Cd}$ is easily acquired by root systems of plants through plasma membrane transporters (Kim et al. 2002, Song et al. 2017). Then Cd is transported to shoots driven by transpiration (Liu et al. 2016, Salt et al. 1995). There were found positive and linear relationships between the transpiration rate and the $\mathrm{Cd}$ accumulation in the shoots (Lai 2015, Liu et al. 2016). The more Cd available to be absorbed in the rooting medium, the more $\mathrm{Cd}$ can be acquired by the roots (Soudek et al. 2014), which is consistent with our observation. However, the Cd concentrations in the roots were significantly higher than those in the shoots, and the TF of the sweet sorghum was about 0.2 under different $\mathrm{Cd}$ concentrations (Fig. 1A). It means that the sweet sorghum could mainly accumulate $\mathrm{Cd}$ in the roots, which could act as a major protective mechanism to reduce the $\mathrm{Cd}$ transport to shoots (Pinto et al. 2004). However, the excess $\mathrm{Cd}$ in the plants can profoundly interfere with a series of biochemical and physiological processes, such as inactivation enzymes activity, disturbance in nutrient uptake, and inhibition of photosynthesis (Jia et al. 2016, Parmar et al. 2013, Soudek et al. 2014, Siedlecka and Krupa 1999). This leads to a significant reduction of the biomass, or even to death of the plant under high $\mathrm{Cd}$ concentrations. In this study, the morphological characteristics of sweet sorghum were significantly changed by the $\mathrm{Cd}$ treatments. The root and shoot length, leaf area, root and shoot mass, and the number of leaves were significantly lowered with the increase of the $\mathrm{Cd}$ concentrations in Hoagland solution. Under 50 and 100 $\mu \mathrm{M}$ Cd treatments, the shoot length decreased by 20.4 and $44.5 \%$, the shoot mass decreased by 21.8 and $48.2 \%$, respectively (Table 1). Our results are consistent with those of Pinto et al. (2004) who reported that a significant decrease of biomass was observed for sorghum grown in nutrient solutions with $10 \mathrm{mg}(\mathrm{Cd}) \mathrm{L}^{-1}$. Due to the peroxide $(2: 1, \mathrm{v} / \mathrm{v})$ at $160^{\circ} \mathrm{C}$ for $5 \mathrm{~h}$. Then the $\mathrm{Cd}$ concentrations were determined, using an inductive coupled plasma mass spectrometer (Agilent 7700X, Agilent Technologies, USA). Three measurements were made for each treatment, and the results were averaged.

Statistical analysis: Translocation factor (TF) was used to present the ability of plants to translocate heavy metal from roots to shoots. It was calculated using the formula: $\mathrm{TF}=$ $\mathrm{Cd}$ concentrations in shoots $\left[\mathrm{mg} \mathrm{g}^{-1}(\mathrm{DM})\right] / \mathrm{Cd}$ concentrations in roots $\left[\mathrm{mg} \mathrm{g}^{-1}(\mathrm{DM})\right]$. Data were subjected to an analysis of variance (ANOVA), using SPSS 22. And significant differences between mean values were determined through least significant difference (LSD) test. Differences were considered statistically significant when $P<0.05$.

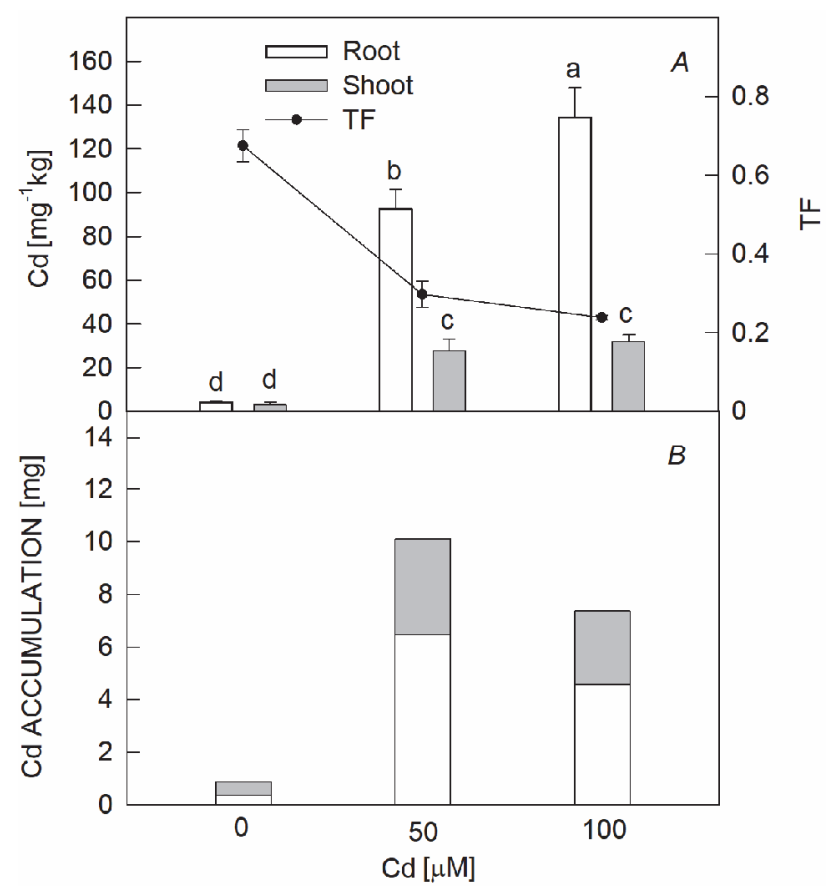

Fig. 1. The translocation factor (TF, $A$, right axis), Cd concentration in root and shoot ( $A$, left axis) and accumulation $(B)$ in the root and shoot of sweet sorghum plants after being treated with different concentrations of $\mathrm{Cd}$ for $15 \mathrm{~d}$. The means $\pm \mathrm{SE}$ of three replicates are shown. The different letters indicate significant differences at $P<0.05$ between different treatments.

significantly declined dry mass, the $\mathrm{Cd}$ accumulation in the roots under $100 \mu \mathrm{M} \mathrm{Cd}$ concentration was lower than that under $50 \mu \mathrm{M}$ (Fig. 1B).

Previous research has suggested that high $\mathrm{Cd}$ concentrations $\left[100 \mathrm{mg}(\mathrm{Cd}) \mathrm{kg}^{-1}\right.$ (soil)] (Gill et al. 2012). As a $\mathrm{C}_{4}$ crop, sweet sorghum has high photosynthetic efficiency. In the present study, the $P_{\mathrm{N}}, g_{\mathrm{s}}$, and $E$ in the leaves of sweet sorghum decreased significantly by Cd treatment. The $P_{\mathrm{N}}$ decreased by 23.6 and $38 \%$ under 50 and $100 \mu \mathrm{M} \mathrm{Cd}$ 
Table 1. The root length, shoot length, leaf area, root mass, shoot mass, and number of leaves of sweet sorghum plants after being treated with different concentrations of $\mathrm{Cd}$ for $15 \mathrm{~d}$. The means $\pm \mathrm{SE}$ of 15 replicates are shown. The different letters indicate significant differences at $P<0.05$ between different treatments.

\begin{tabular}{lllllll}
\hline Cd $[\mu \mathrm{m}]$ & Root length $[\mathrm{cm}]$ & Shoot length $[\mathrm{cm}]$ & Leaf area $\left[\mathrm{cm}^{2}\right]$ & Root mass $[\mathrm{g}]$ & Shoot mass $[\mathrm{g}]$ & Number of leaves \\
\hline 0 & $17.63 \pm 1.69^{\mathrm{a}}$ & $42.00 \pm 4.44^{\mathrm{a}}$ & $19.92 \pm 3.63^{\mathrm{a}}$ & $0.087 \pm 0.003^{\mathrm{a}}$ & $0.166 \pm 0.003^{\mathrm{a}}$ & $5.20 \pm 1.03^{\mathrm{a}}$ \\
50 & $17.75 \pm 4.80^{\mathrm{a}}$ & $33.42 \pm 3.11^{\mathrm{b}}$ & $15.80 \pm 3.92^{\mathrm{b}}$ & $0.070 \pm 0.002^{\mathrm{b}}$ & $0.131 \pm 0.004^{\mathrm{b}}$ & $3.00 \pm 0.52^{\mathrm{b}}$ \\
100 & $12.57 \pm 2.43^{\mathrm{b}}$ & $23.31 \pm 3.24^{\mathrm{c}}$ & $12.48 \pm 2.45^{\mathrm{c}}$ & $0.034 \pm 0.002^{\mathrm{c}}$ & $0.086 \pm 0.003^{\mathrm{c}}$ & $2.90 \pm 0.74^{\mathrm{c}}$ \\
\hline
\end{tabular}

treatments (Fig. $2 A$ ), respectively, while $E$ decreased by 35.3 and $47.5 \%$, respectively. The reduction of $g_{\mathrm{s}}$ could result in the decrease of $P_{\mathrm{N}}$ and $E$. It was further supported by fact the $g_{\mathrm{s}}$ was well correlated with the $P_{\mathrm{N}}\left(R^{2}=0.98\right)$ and $E\left(R^{2}=0.98\right)$. Meanwhile, Chl contents were reduced by $\mathrm{Cd}$. In this study, spectral reflectance techniques was adopted to gain insights of the change of Chl contents in the leaves. The spectral curves of the sweet sorghum leaves increased significantly in a visible range (500-700 $\mathrm{nm}$ ), in dependence on Chl contents in the leaves, after treatments with different concentrations of $\mathrm{Cd}$ (Fig. 3A). From the difference in reflectance, we could observe the significant changes caused by the Cd treatment (Fig. 3B). The PRI can serve as a good indicator of the change in photosynthetic apparatus under environmental stress (Gamon et al. 1992, Zhang et al. 2017). In this study, the decrease of PRI in the leaves of sweet sorghum under $\mathrm{Cd}$ stress was similar to that of $P_{\mathrm{N}}$ (Fig. $4 A$ ), which is demonstrated by the significant correlation between the PRI and $P_{\mathrm{N}}$ in the leaves $\left(R^{2}=1.00\right)$. The significantly decreased $\mathrm{mND}_{705}$ (Fig. $4 B$ ) and $\mathrm{mSR}_{705}$ (Fig. 4C), which have a high correlation with $\mathrm{Chl}$ contents across different leaf types (Sims and Gamon 2002), indicated that the Chl content in the leaves decreased significantly by the $\mathrm{Cd}$ treatment. Cd could induce the inhibition of Chl biosynthesis and the substitution of the central $\mathrm{Mg}^{2+}$ in Chl molecule (Küpper et al. 1996, Wang et al. 2014). The decrease of the Chl content can partly account for the decrease of $P_{\mathrm{N}}$, which is in agreement with previous reports (Wang et al. 2014).

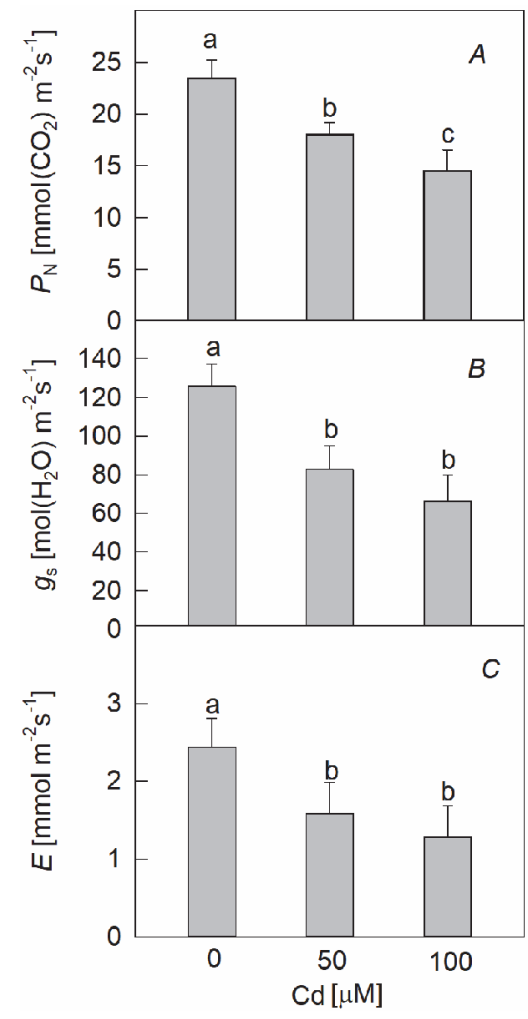

Fig. 2. The net photosynthetic rate $\left(P_{\mathrm{N}}, A\right)$, stomatal conductance $\left(g_{\mathrm{s}}, B\right)$, and transpiration rate $(E, C)$ in the leaves of sweet sorghum plants after being treated with different concentrations of $\mathrm{Cd}$ for $15 \mathrm{~d}$. The means $\pm \mathrm{SE}$ of five replicates are shown. The different letters indicate significant differences at $P<0.05$ between different treatments.

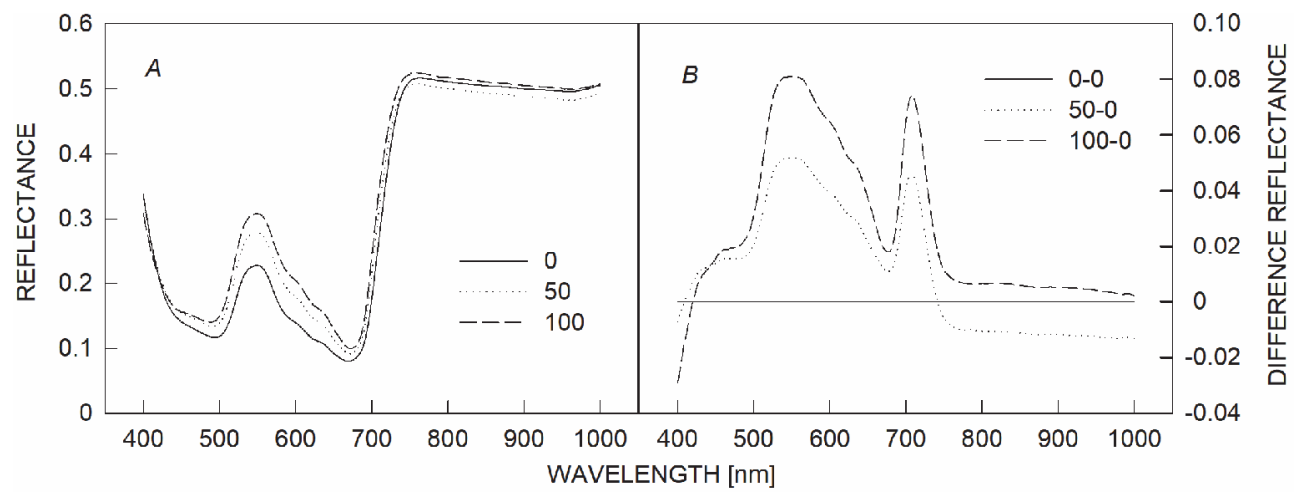

Fig. 3. The reflectance $(A)$ and difference in reflectance $(B)$ in the leaves of sweet sorghum plants after being treated with different concentrations of $\mathrm{Cd}$ for $15 \mathrm{~d}$. Each curve represents the average of thirty independent measurements. 


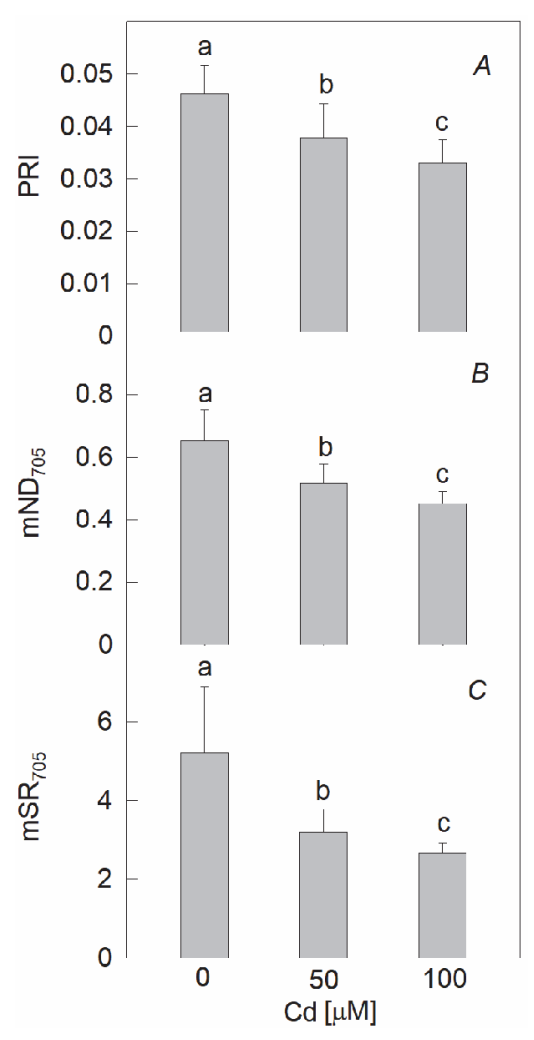

Fig. 4. The photochemical reflectance index (PRI, $A$ ), modified red-edge ratio $\left(\mathrm{mSR}_{705}, B\right)$, and modified red-edge normalized difference vegetation index $\left(\mathrm{mND}_{705}, C\right)$ in the leaves of sweet sorghum plants after being treated with different concentrations of $\mathrm{Cd}$ for $15 \mathrm{~d}$. The means $\pm \mathrm{SE}$ of thirty replicates are shown. The different letters indicate significant differences at $P<0.05$ between different treatments.

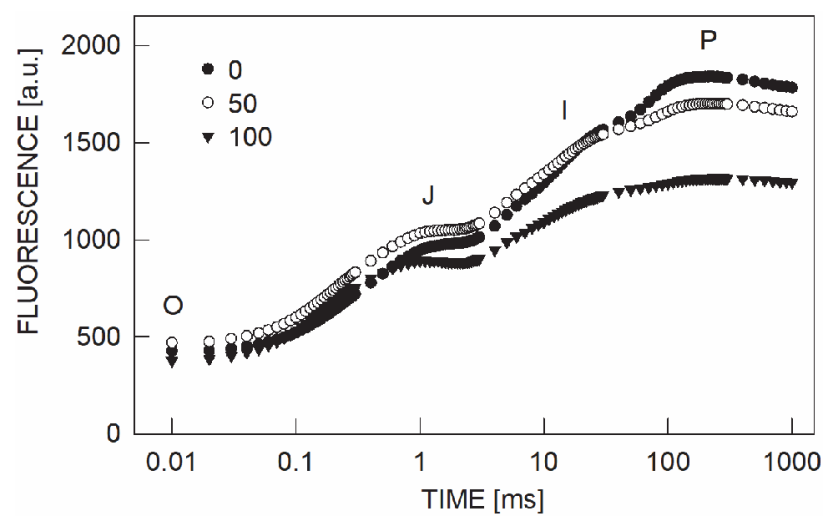

Fig. 5. The chlorophyll $a$ fluorescence rise kinetics (OJIP) of sweet sorghum leaves after being treated with different concentrations of $\mathrm{Cd}$ for $15 \mathrm{~d}$. Each curve represents the average of 15 independent measurements.

$\mathrm{Cd}$ in chloroplasts could interact with $\mathrm{Chl}$-protein complexes and disrupt energy absorption and transfer in photosystems (Bashir et al. 2015). In this study, we estimated photosynthetic efficiency of Cd-treated plants by $\mathrm{Chl} a$ fluorescence technique, which is a very sensitive
Table 2. The $\varphi_{\mathrm{P} o}, \Psi_{\mathrm{E} o}, \delta_{\mathrm{Ro}}, \mathrm{PI}_{\mathrm{abs}}, \mathrm{RC} / \mathrm{CS}_{\mathrm{o}}, \mathrm{DI}_{\mathrm{o}} / \mathrm{RC}, \mathrm{ABS} / \mathrm{RC}$, $\mathrm{TR}_{0} / \mathrm{RC}$, and $\mathrm{ET}_{\mathrm{o}} / \mathrm{RC}$ in the leaves of sweet sorghum after treated with different concentrations of $\mathrm{Cd}$ for $15 \mathrm{~d}$. Fifteen replicate measurements were made for each treatment, and the results were averaged. The different letters indicate significant differences at $P<0.05$ between different treatments.

\begin{tabular}{llll}
\hline \multirow{2}{*}{ Parameter } & \multicolumn{3}{l}{ Cd concentration $[\mu \mathrm{M}]$} \\
& 0 & 50 & 100 \\
\hline$\varphi_{\text {Po }}$ & $0.75 \pm 0.02^{\mathrm{a}}$ & $0.69 \pm 0.02^{\mathrm{b}}$ & $0.67 \pm 0.02^{\mathrm{c}}$ \\
$\Psi_{\text {Eo }}$ & $0.62 \pm 0.01^{\mathrm{a}}$ & $0.55 \pm 0.02^{\mathrm{b}}$ & $0.49 \pm 0.03^{\mathrm{c}}$ \\
$\delta_{\text {Ro }}$ & $0.32 \pm 0.03^{\mathrm{a}}$ & $0.24 \pm 0.04^{\mathrm{b}}$ & $0.20 \pm 0.05^{\mathrm{c}}$ \\
$\mathrm{RC}_{\mathrm{CS}}$ & $173.41 \pm 7.48^{\mathrm{a}}$ & $153.33 \pm 9.06^{\mathrm{b}}$ & $103.37 \pm 20.43^{\mathrm{c}}$ \\
$\mathrm{ABS}_{\mathrm{N} C}$ & $2.67 \pm 0.21^{\mathrm{c}}$ & $3.39 \pm 0.16^{\mathrm{b}}$ & $4.30 \pm 0.53^{\mathrm{a}}$ \\
$\mathrm{TR}_{\mathrm{o}} / \mathrm{RC}$ & $1.99 \pm 0.11^{\mathrm{c}}$ & $2.35 \pm 0.09^{\mathrm{b}}$ & $2.87 \pm 0.33^{\mathrm{a}}$ \\
$\mathrm{ET}_{\mathrm{o}} / \mathrm{RC}$ & $1.24 \pm 0.06^{\mathrm{b}}$ & $1.29 \pm 0.08^{\mathrm{b}}$ & $1.41 \pm 0.19^{\mathrm{a}}$ \\
$\mathrm{DI}_{\mathrm{o}} / \mathrm{RC}$ & $0.67 \pm 0.10^{\mathrm{c}}$ & $1.04 \pm 0.09^{\mathrm{b}}$ & $1.43 \pm 0.23^{\mathrm{a}}$ \\
PIabs & $1.89 \pm 0.35^{\mathrm{a}}$ & $0.83 \pm 0.10^{\mathrm{b}}$ & $0.47 \pm 0.12^{\mathrm{c}}$ \\
\hline
\end{tabular}

to stress and can gain insights of structure, conformation, and function of photosynthetic apparatus (Stirbet and Govindjee 2011, Salvatori et al. 2015, Kalaji et al. 2016). The change of the shape of $\mathrm{Chl} a$ fluorescence transients of sweet sorghum leaves by $\mathrm{Cd}$ treatment suggested that $\mathrm{Cd}$ significantly influenced the performance of photosynthetic machinery (Fig. 5). In order to reveal further a damage to PSII, the transients were analyzed according to the JIP-test. The parameters derived from Chl $a$ fluorescence were analyzed and shown in Table 2. The results showed Cd-induced increase of $\mathrm{DI}_{0} / \mathrm{RC}, \mathrm{ABS} / \mathrm{RC}$, $\mathrm{TR}_{0} / \mathrm{RC}$, and $\mathrm{ET}_{\mathrm{o}} / \mathrm{RC}$, as well as a significant decrease of the $\varphi_{\mathrm{Po}}, \Psi_{\mathrm{Eo}}, \delta_{\mathrm{Ro}}, \mathrm{PI}_{\mathrm{abs}}$, and $\mathrm{RC} / \mathrm{CS}_{\mathrm{o}}$. The decrease in $\varphi_{\mathrm{Po}}$ indicated that the photosynthetic efficiency of sweet sorghum was lowered, implying that the primary photochemical reactions were affected with the higher $\mathrm{Cd}$ concentration. $\Psi_{\mathrm{E}}$ represents the probability that an absorbed photon moves an electron further than $\mathrm{Q}_{\mathrm{A}^{-}}$, and $\delta_{\text {Ro }}$ represents the probability that an electron is transported from the reduced intersystem electron acceptors to the final electron acceptors of PSI (Strasser et al. 2004). The decrease in $\Psi_{\text {Eo }}$ and $\delta_{\text {Ro }}$ of sweet sorghum leaves under $\mathrm{Cd}$ treatments suggested that the electron transport of PSII was blocked due to $\mathrm{Q}^{-}$accumulation. Whereas, the increase in $\mathrm{DI}_{0} / \mathrm{RC}, \mathrm{ABS} / \mathrm{RC}, \mathrm{TR}_{0} / \mathrm{RC}$, and $\mathrm{ET}_{0} / \mathrm{RC}$ suggests that a fraction of active reaction centers was inactivated, which was also confirmed by decreases in $\mathrm{RC} / \mathrm{CS}_{0}$. It was supported by the decreased $\mathrm{Chl}$ contents in leaves under $\mathrm{Cd}$ treatments (Fig. 4) and the decrease of $\mathrm{Chl}$ $a$ content was more pronounced than that of $\mathrm{Chl} b$ under $\mathrm{Cd}$ treatments (He et al. 2008). The performance index, $\mathrm{PI}_{\mathrm{abs}}$, which combines three main structural and functional characteristics of PSII $\left(\mathrm{ABS} / \mathrm{RC}, \varphi_{\mathrm{Po}}, \Psi_{\mathrm{EO}}\right)$, is closely related to the ability of energy conservation and the activity of photosynthetic apparatus. A significant decrease in the $\mathrm{PI}_{\mathrm{abs}}$ of sweet sorghum leaves with the enhanced $\mathrm{Cd}$ concentrations indicated that the electron transfers were blocked. Previous research has suggested 
that $\mathrm{Cd}$ could exert multiple effects on both donor and acceptor sides of the PSII (Pagliano et al. 2006, Sigfridsson et al. 2004). Cd could exchange with $\mathrm{Ca}^{2+}$ in oxygen-evolving complex on the donor side and decrease the rate of electron transfer from $Q_{A}$ to $Q_{B}$ due to interaction with non-heme $\mathrm{Fe}$ and conformational modification of $\mathrm{Q}_{\text {в }}$ pocket (Parmar et al. 2013).

However, different plant species (Li et al. 1997), even cultivars (Franić et al. 2017), have different Cd tolerance. So further investigation is needed to elucidate the mechanism of the $\mathrm{Cd}$ distribution in the different sweet

\section{References}

Almodares A., Hadi M.R.: Production of bioethanol from sweet sorghum: a review. - Afr. J. Agr. Res. 4: 772-780, 2009.

An Y.J.: Soil ecotoxicity assessment using cadmium sensitive plants. - Environ. Pollut. 127: 21-26, 2004.

Bashir H., Qureshi M.I., Ibrahim, M.M. et al.: Chloroplast and photosystems: Impact of cadmium and iron deficiency. Photosynthetica 53: 321-335, 2015.

Chen S., Yang J., Zhang M. et al.: Classification and characteristics of heat tolerance in Ageratina adenophora populations using fast chlorophyll $a$ fluorescence rise O-J-I-P. - Environ. Exp. Bot. 122: 126-140, 2016.

Franić M., Galić V., Mazur M. et al.: Effects of excess cadmium in soil on JIP-test parameters, hydrogen peroxide content and antioxidant activity in two maize inbreds and their hybrid. Photosynthetica 55: 1-10, 2017.

Gamon J.A., Peñuelas J., Field C.B.: A narrow-waveband spectral index that tracks diurnal changes in photosynthetic efficiency. - Remote Sens. Environ. 41: 35-44, 1992.

Gill S.S., Khan N.A., Tuteja N.: Cadmium at high dose perturbs growth, photosynthesis and nitrogen metabolism while at low dose it up regulates sulfur assimilation and antioxidant machinery in garden cress (Lepidium sativum L.). - Plant Sci. 182: 112-120, 2012.

Gomes H.I.: Phytoremediation for bioenergy: challenges and opportunities. - Environ. Technol. 1: 59-66, 2012.

Gomes M.A.D.C., Hauser-Davis R.A., Souza A.N.D. et al.: Metal phytoremediation: General strategies, genetically modified plants and applications in metal nanoparticle contamination. - Ecotoxicol. Environ. Safe. 134: 133-147, 2016.

Guo Y.Y., Tian S.S., Liu S.S. et al.: Energy dissipation and antioxidant enzyme system protect photosystem II of sweet sorghum under drought stress. - Photosynthetica 56: online first, 2018.

He J.Y., Ren Y.F., Zhu C. et al.: Effect of $\mathrm{Cd}$ on growth, photosynthetic gas exchange, and chlorophyll fluorescence of wild and Cd-sensitive mutant rice. - Photosynthetica 46: 466$470,2008$.

Jia W., Lv S., Feng J. et al.: Morphophysiological characteristic analysis demonstrated the potential of sweet sorghum (Sorghum bicolor (L.) Moench) in the phytoremediation of cadmium-contaminated soils. - Environ. Sci. Pollut. R. 23: 18823-18831, 2016.

Küpper H., Küpper F., Spiller M.: Environmental relevance of heavy metal-substituted chlorophylls using the example of water plants. - J. Exp. Bot. 47: 259-266, 1996.

Kalaji H.M., Jajoo A., Oukarroum A. et al.: Chlorophyll $a$ fluorescence as a tool to monitor physiological status of plants under abiotic stress conditions. - Acta Physiol. Plant. 38: 1-11, sorghum genotypes and choose cultivars according to the environmental conditions.

Conclusion: The results demonstrated that the $\mathrm{Cd}$ concentration in the sweet sorghum seedling increased with the increasing $\mathrm{Cd}$ concentration in the nutrition solution and more $\mathrm{Cd}$ accumulated in the roots. The higher $\mathrm{Cd}$ concentration decreased $\mathrm{Chl}$ contents and obstructed electron transport in the leaves, leading to the decrease of photosynthetic activity.

2016.

Kim Y.Y., Yang Y.Y., Lee Y.: Pb and Cd uptake in rice roots. Physiol. Plantarum 116: 368-372, 2002.

Lai H.Y.: Effects of leaf area and transpiration rate on accumulation and compartmentalization of cadmium in Impatiens walleriana. - Water Air Soil Pollut. 226: 2246, 2015.

Li Y.M., Chaney R.L., Schneiter A.A. et al.: Screening for low grain cadmium phenotypes in sunflower, durum wheat and flax. - Euphytica 94: 23-30, 1997.

Liu H., Wang H., Ma Y. et al.: Role of transpiration and metabolism in translocation and accumulation of cadmium in tobacco plants (Nicotiana tabacum L.). - Chemosphere 144: 1960-1965, 2015.

Luo L., Ma Y., Zhang S. et al.: An inventory of trace element inputs to agricultural soils in China. - J. Environ. Manage. 90: 2524-2530, 2009.

Lysenko E.A., Klaus A.A., Pshybytko N.L. et al.: Cadmium accumulation in chloroplasts and its impact on chloroplastic processes in barley and maize. - Photosynth. Res. 125: 291303, 2015.

Marchiol L., Fellet G., Perosa D. et al.: Removal of trace metals by Sorghum bicolor and Helianthus annuus in a site polluted by industrial wastes: A field experience. - Plant Physiol. Bioch. 45: 379-387, 2007.

Pagliano C., Raviolo M., Dalla Vecchia F. et al.: Evidence for PSII donor-side damage and photoinhibition induced by cadmium treatment on rice (Oryza sativa L.). - J. Photoch. Photobio. B 84: 70-78, 2006.

Parmar P., Kumari N., Sharma V.: Structural and functional alterations in photosynthetic apparatus of plants under cadmium stress. - Bot. Stud. 54: 1-6, 2013.

Pinto A.P., Mota A.M., de Varennes A. et al.: Influence of organic matter on the uptake of cadmium, zinc, copper and iron by sorghum plants. - Sci. Total Environ. 326: 239-247, 2004.

Salt D.E., Prince R.C., Pickering I.J. et al.: Mechanisms of cadmium mobility and accumulation in Indian mustard. - Plant Physiol. 109: 1427-1433, 1995.

Salvatori E., Fusaro L., Strasser R.J. et al.: Effects of acute $\mathrm{O}_{3}$ stress on PSII and PSI photochemistry of sensitive and resistant snap bean genotypes (Phaseolus vulgaris L.), probed by prompt chlorophyll $a$ fluorescence and $820 \mathrm{~nm}$ modulated reflectance. - Plant Physiol. Bioch. 97: 368-377, 2015.

Satarug S., Garrett S.H., Sens M.A. et al.: Cadmium, environmental exposure, and health outcomes. - Environ. Health Perspect. 118: 182-190, 2010.

Sathya A., Kanaganahalli V., Rao P.S. et al.: Cultivation of sweet sorghum on heavy metal-contaminated soils by phytoremediation approach for production of bioethanol. - In: Prasad 
M.N.V. (ed.): Bioremediation and Bioeconomy. Pp. 271-292. Elsevier, Amsterdam 2016.

Sigfridsson K.G.V., Bernát G., Mamedov F. et al.: Molecular interference of $\mathrm{Cd}^{2+}$ with photosystem II. - BBA-Bioenergetics 1659: 19-31, 2004.

Siedlecka A., Krupa Z.: Cd/Fe interaction in higher plants its consequences for the photosynthetic apparatus. Photosynthetica 36: 321-331, 1999.

Silva A.J., Nascimento C.W. A., Gouveia-Neto A.S.: Assessment of cadmium phytotoxicity alleviation by silicon using chlorophyll $a$ fluorescence. - Photosynthetica 55: 648-654, 2017.

Sims D.A., Gamon J.A.: Relationships between leaf pigment content and spectral reflectance across a wide range of species, leaf structures and developmental stages. - Remote Sens. Environ. 81: 337-354, 2002.

Song Y., Jin L., Wang X.: Cadmium absorption and transportation pathways in plants. - Int. J. Phytoremediat. 19: 133-141, 2017.

Soudek P., Petrová Š., Vaňková R. et al.: Accumulation of heavy metals using Sorghum sp. - Chemosphere 104: 15-24, 2014.

Stirbet A., Govindjee: On the relation between the Kautsky effect (chlorophyll $a$ fluorescence induction) and Photosystem II: Basics and applications of the OJIP fluorescence transient. - J. Photoch. Photobio. B 104: 236-257, 2011.

Strasser R.J., Tsimilli-Michael M., Srivastava A.: Analysis of the chlorophyll $a$ fluorescence transient. - In: Papageorgiou G.C., Govindjee (ed.): Chlorophyll $a$ Fluorescence: A Signature of Photosynthesis, Vol. 19. Pp. 321-362. Springer, Dordrecht 2004.

Tian Y.L., Zhang H.Y., Guo W. et al.: Morphological responses, biomass yield, and bioenergy potential of sweet sorghum cultivated in cadmium-contaminated soil for biofuel. - Int. J. Green Energy 12: 577-584, 2015.

van Ginneken L., Meers E., Guisson R. et al.: Phytoremediation for heavy metal-contaminated soils combined with bioenergy production. - J. Environ. Eng. Landsc. 15: 227-236, 2007.
Vigliotta G., Matrella S., Cicatelli A. et al.: Effects of heavy metals and chelants on phytoremediation capacity and on rhizobacterial communities of maize. - J. Environ. Manage. 179: 93-102, 2016.

Wang H., Zhao S.C., Liu R.L. et al.: Changes of photosynthetic activities of maize (Zea mays L.) seedlings in response to cadmium stress. - Photosynthetica 47: 277-283, 2009.

Wang X., Chen C., Wang J.: Cadmium phytoextraction from loam soil in tropical southern China by Sorghum bicolor. - Int. J. Phytoremediat. 19: 572-578, 2017.

Wang Y., Jiang X., Li K. et al.: Photosynthetic responses of Oryza sativa L. seedlings to cadmium stress: physiological, biochemical and ultrastructural analyses. - BioMetals 27: 389401, 2014.

Xue Z.C., Gao H.Y., Zhang L.T.: Effects of cadmium on growth, photosynthetic rate and chlorophyll content in leaves of soybean seedlings. - Biol. Plantarum 57: 587-590, 2013.

Xue Z., Gao H., Zhao S.: Effects of cadmium on the photosynthetic activity in mature and young leaves of soybean plants. - Environ. Sci. Pollut. R. 21: 4656-4664, 2014.

Yuan X., Wang J., Shang Y.e. et al.: Health risk assessment of cadmium via dietary intake by adults in China. - J. Sci. Food Agr. 94: 373-380, 2014.

Zhang C., Filella I., Liu D. et al.: Photochemical reflectance index (PRI) for detecting responses of diurnal and seasonal photosynthetic activity to experimental drought and warming in a Mediterranean shrubland. - Remote Sens.-Basel 9: 1189, 2017.

Zhong M.S., Jiang L., Han D. et al.: Cadmium exposure via diet and its implication on the derivation of health-based soil screening values in China. - J. Expo. Sci. Env. Epid. 25: 433442, 2015.

Zhuang P., Shu W., Li Z. et al.: Removal of metals by sorghum plants from contaminated land. - J. Environ. Sci. 21: 14321437,2009

\section{Appendix}

Formulae and explanation the technical data of the OJIP curves and the selected JIP-test parameters used in this study.

\begin{tabular}{|c|c|}
\hline Fluorescence parameter & Description \\
\hline $\mathrm{F}_{\mathrm{t}}$ & Fluorescence emission from a dark-adapted leaf at the time $t$ \\
\hline $\mathrm{F}_{\mathrm{o}}$ & Fluorescence intensity at $20 \mu \mathrm{s}$ \\
\hline FJ & Fluorescence intensity at the $J$ step (at $2 \mathrm{~ms}$ ) \\
\hline $\mathrm{F}_{\mathrm{I}}$ & Fluorescence intensity at the I step (at $30 \mathrm{~ms}$ ) \\
\hline $\mathrm{F}_{\mathrm{m}}$ & Maximal fluorescence intensity \\
\hline $\mathrm{M}_{\mathrm{o}}=4\left(\mathrm{~F}_{300 \text { us }}-\mathrm{F}_{\mathrm{o}}\right) /\left(\mathrm{F}_{\mathrm{m}}-\mathrm{F}_{\mathrm{o}}\right)$ & Slope of the curve at the origin of the relative variable fluorescence rise \\
\hline $\mathrm{V}_{\mathrm{t}}=\left(\mathrm{F}_{\mathrm{t}}-\mathrm{F}_{\mathrm{o}}\right) /\left(\mathrm{F}_{\mathrm{m}}-\mathrm{F}_{\mathrm{o}}\right)$ & Relative variable fluorescence at the time $t$ \\
\hline$\varphi_{P_{0}}=\left(F_{m}-F_{0}\right) / F_{m}$ & Maximum quantum yield for primary photochemistry \\
\hline$\Psi_{\mathrm{Eo}}=1-\mathrm{V}_{\mathrm{J}}$ & Probability that an electron moves further than $\mathrm{Q}_{A^{-}}$ \\
\hline$\delta_{\mathrm{Ro}}=\left(1-\mathrm{V}_{\mathrm{I}}\right) /\left(1-\mathrm{V}_{\mathrm{J}}\right)$ & $\begin{array}{l}\text { Probability that an electron is transported from the reduced intersystem } \\
\text { electron acceptors to the final electron acceptors of PSI }\end{array}$ \\
\hline $\mathrm{RC} / \mathrm{Cs}_{\mathrm{o}}=\varphi_{\mathrm{Po}_{\mathrm{o}}}\left(\mathrm{V}_{\mathrm{J}} / \mathrm{M}_{\mathrm{o}}\right) \mathrm{F}_{\mathrm{o}}$ & $\mathrm{Q}_{\mathrm{A}}$-reducing $\mathrm{RCs}$ per $\mathrm{CS}$ \\
\hline $\mathrm{ABS} / \mathrm{RC}=\mathrm{M}_{\mathrm{o}}\left(1 / \mathrm{V}_{\mathrm{J}}\right)\left(1 / \varphi_{\mathrm{Po}}\right)$ & Absorption flux per RC \\
\hline $\mathrm{TR}_{\mathrm{o}} / \mathrm{RC}=\mathrm{M}_{\mathrm{o}}\left(1 / \mathrm{V}_{\mathrm{J}}\right)$ & Trapped energy flux per $\mathrm{RC}$ at $\mathrm{t}=0$ \\
\hline $\mathrm{ET}_{\mathrm{o}} / \mathrm{RC}=\mathrm{M}_{\mathrm{o}}\left(1 / \mathrm{V}_{\mathrm{J}}\right) \Psi_{\mathrm{Eo}}$ & Electron transport flux per $\mathrm{RC}$ at $\mathrm{t}=0$ \\
\hline $\mathrm{DI}_{\mathrm{o}} / \mathrm{RC}=(\mathrm{ABS} / \mathrm{RC})-\left(\mathrm{TR}_{\mathrm{o}} / \mathrm{RC}\right)$ & Dissipated energy flux per $\mathrm{RC}$ at $\mathrm{t}=0$ \\
\hline $\mathrm{PI}_{\mathrm{abs}}=(\mathrm{RC} / \mathrm{ABS})\left[\varphi_{\mathrm{P}_{\mathrm{o}}} /\left(1-\varphi_{\mathrm{P}_{\mathrm{o}}}\right)\right][\Psi$ & The performance index \\
\hline
\end{tabular}

